forceps, but it was probably caused by the placenta praevia forceps on account of no axis traction attachment being used, the blade being too sharp in front and the position being left occipitoposterior.

In this case the placenta praevia forceps were very easily applied, and the pains came on at once and at short intervals. The forceps seemed to act as a gentle dilator of the cervix to stimulate uterine contractions, and a slight amount of traction kept up sufficient pressure of the head on the placenta to prevent hemorrhage.

In modifying a pair of obstetric forceps, it would be preferable to have one with a lock that allows the shanks to come closely together, as it can be applied through a smaller opening than one made with the English lock.

116 Ford Street.

\section{A NEW FRAME FOR TUBERCULOSIS OF THE SPINE}

Gordon N. Morrill, M.D., Cleveland

The rather general acceptance of the Whitman-Bradford frame as the best appliance for hyperextension of tuberculous spines leads me to describe a frame which in my experience has proved superior to it in every way for treatment of this disease in children.

The principal reasons for dissatisfaction with the Whitman modification of Bradford's appliance are obvious to those who have had experience with it, namely: (1) the impossi-

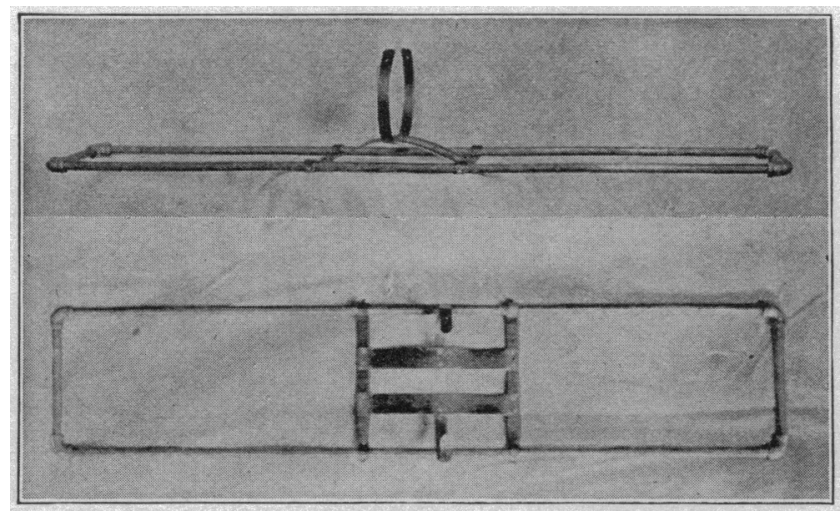

Fig. 1.-Above, Bradford foundation with the new support attached; below, top view of frame.

bility of holding the kyphos up, owing to the inevitable sagging of the canvas; (2) difficulty in ascertaining the position of the kyphos after the child is strapped into place, because of the thick padding underneath; (3) the necessarily tight apron holding the patient in position, with the result that not only is breathing made difficult, but the body is flattened and compressed to such a degree that normal development is impossible; (4) bad ventilation caused by direct bodily contact with the canvas cover and rubber sheeting; (5) the fact that the entire frame must be bent to the corrective angle, and (6) the great danger of genu recurvatum, owing to the rigid fixation of the knees in a hyperextended position.

Each of these defects is completely eliminated in a frame devised by Dr. H. O. Feiss and myself. For eight years I have used it exclusively in all acute cases of dorsal and lumbar tuberculous spines in my work at Lakeside and Rainbow hospitals, with unvarying success and the increasing conviction that it is the most practical device I have yet seen for the purpose.

Because of these excellent results, I feel justified in going considerably into detail in describing the frame and the part it plays in the treatment of Pott's disease in children.

The appliance is constructed on the Bradford frame foundation, which need be made in but two sizes for children under 12. Fastened to the sides of the gas-pipe frame is the support-unit of the device, and this may be moved to any desired position by adjusting four screws holding the cross bars in place (Fig. 1). The support proper is composed of two curved pieces of steel fastened to the cross bars $1 \frac{1}{2}$ or 2 inches apart, leaving sufficient space for the spinous processes. To each side of this support proper is attached one-half the waist band, which serves, not as a means of confining the patient, but of fixation for the perineal and shoulder straps. These are attached as shown in

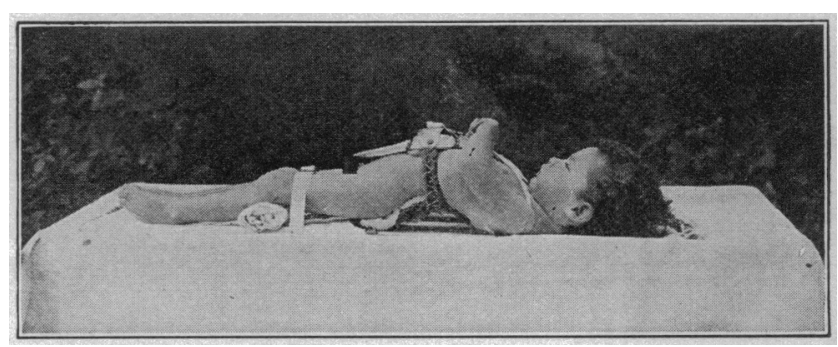

Fig. 2.-Child in position on the frame, showing the arrangement of accessories.

Figure 2, and buckled firmly in place. The knee strap, it should be noted, is placed well above the patellae, thus eliminating the danger of pressure at a sensitive point. An important item, also, is the pad under the knees (Figs. 2, 4 , etc.), to prevent stretching the posterior structures of the knee joints. Strips of felt are used as padding on the spinal support and waist-band; and canvas covers, as well as overslips of finer material, are laced on the ends of the frame. A space is left between the lower of these and the support-unit for the use of the bed-pan, for which the entire frame should be raised on blocks. The child wears shirt and drawers when put on the frame, and the outer garment may be buttoned beneath the support, making it unnecessary that the clothing be so large as to include the entire apparatus.

The many advantages of the frame $I$ have described are easily recognized. Naturally, the convex curve of the two pieces of steel, which may be quickly adjusted for any degree of kyphosis, is the main corrective agent of the device. It tends to restore the normal curve of the spinal column, through exaggerating it to compensate for the deformity. By hyperextension of the spine, and by the rigid convexity of the support, the body weight, pulling in opposite directions, separates the diseased vertebrae-which in itself has a naturally curative effect-and at the same time reduces the kyphos. There is no weight or pressure to flatten the chest or abdomen; therefore, normal development and the body metabolism are not interfered with-facts which are made evident by the increase in weight which has always occurred in these cases.

The raising of the trunk above the frame not only makes good ventilation, but also enables the visiting physician

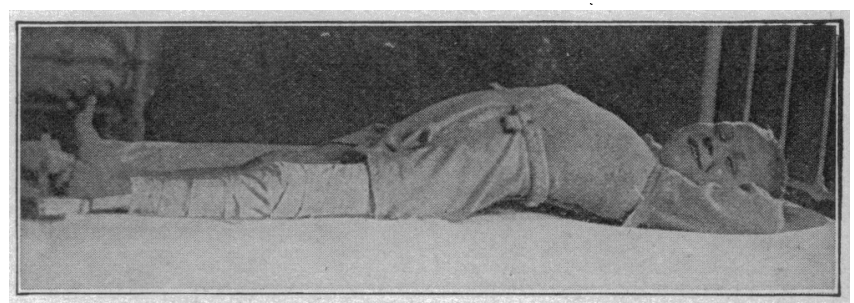

Fig. 3.- Patient having tuberculous spine and hip, with traction on limb.

instantly to ascertain the position of the kyphos in relation to the support.

Moreover, traction may be used without interfering with the patient's position on the frame, as in Figure 3, in which the boy is being treated simultaneously for tuberculosis of the hip and of the spine. In such instances, the frame should be tied at its upper end to the head of the bed, which, together with the perineal straps, makes slipping downward 
impossible. In one case, a child having complete pressure paraplegia with paralysis of the bladder and bowels was so treated, with traction on the legs, and in three weeks the paralysis had practically disappeared.

If this frame is to be used on a bed, it is advisable to put a board under each end to prevent the bed's sagging. But it may be laid on a table quite as well (Figs. 2, 4 and 6).

Beyond seeing that the support fits the deformity, there is little to be done for the patient while on the frame, except that he must be rolled off carefully once every day, and his back bathed with alcohol and powdered with zinc oxid. While this is being done, the child should always take a position resting the elbows on the table, the chin in the hands (Fig. 5), thus keeping the spine in hyperextension until the apparatus is again in place. In rolling the patient both off and on the frame, the nurse places her hand on the chest with her arm supporting the abdomen, and turns the frame with the child. To this treatment and proper adjustment of the support is due the fact that there has never been a pressure sore in my experience with the appliance. If the pressure is correctly applied, there will be merely a slightly reddened area on each side of the kyphos. However, it must be clearly understood that this device is never to be used with, adult patients, as their skin cannot withstand the pressure of the proportionately greater body weight without resulting abrasions.

With caries of the bodies of the vertebrae it is absolutely essential that the patient be kept on the frame at least six months, as the spasm of the erector spinae seldom ceases under that period. Even if this were not true, a shorter

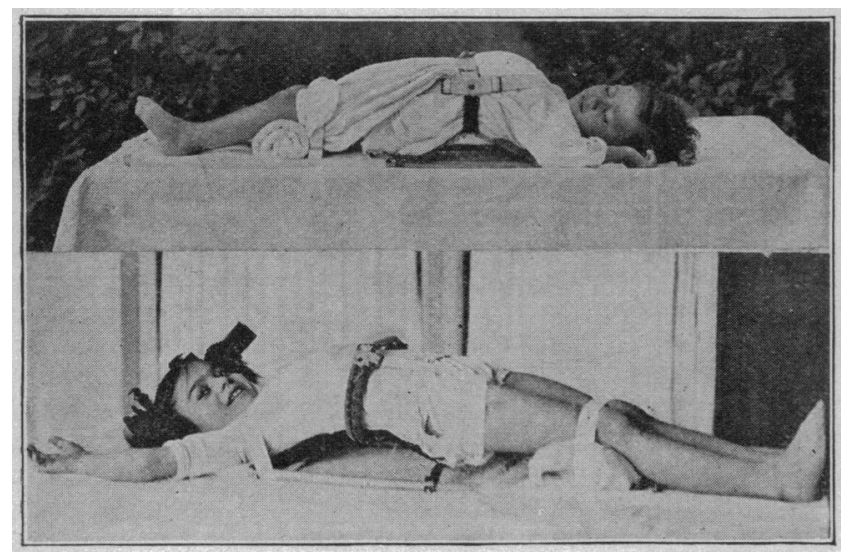

Fig. 4.-Examples of the two sizes of frame used for children under 12; the pad under the knees is important.

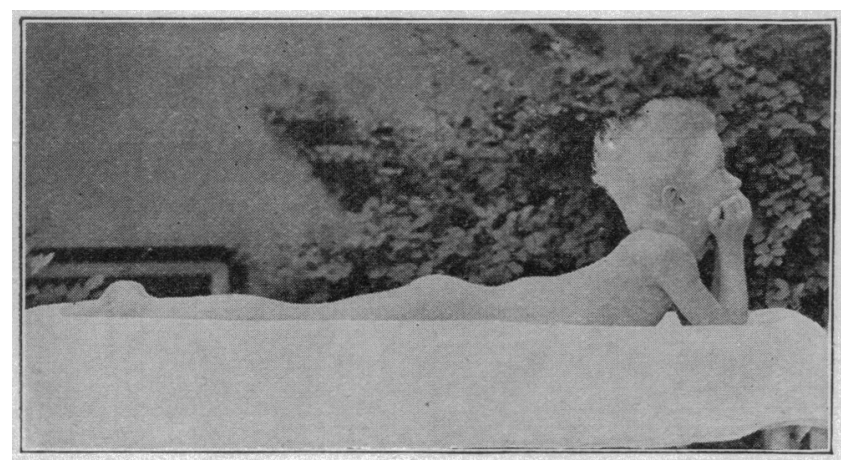

Fig. 5.-Position to be assumed by patient daily while the back is being cared for.

period of recumbency would be unwise, owing to the probability of an exacerbation of the disease. Frequently, as much as a year is required to make certain the best results. Lateral roentgenograms and tracings of the kyphos should be made every two months while the patient is on the frame, increasing the tracings to one a month when the patient has been removed and fitted to a suitable brace. Only in these ways can reliable data on the progress of the disease be secured.

For treatment of tuberculosis of the upper dorsal spines, I use the same frame with a specially adapted support-unit. It differs from the one described only in the curve of the two steel bars, which in this case are bent into a figure $S$ (Fig. 7). With the high point of the curve under the

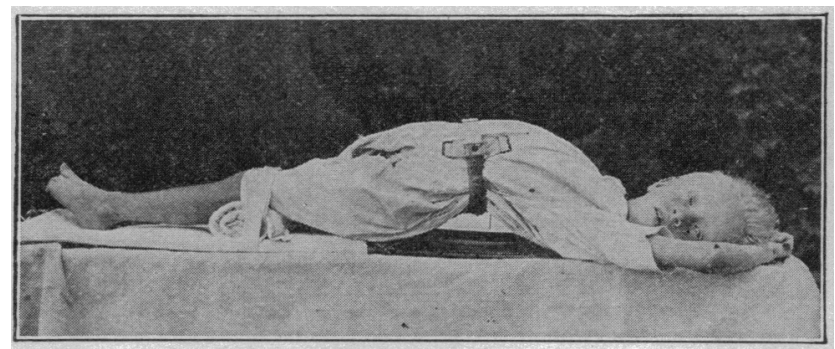

Fig. 6.-Patient in Figure 5 in place on the frame.

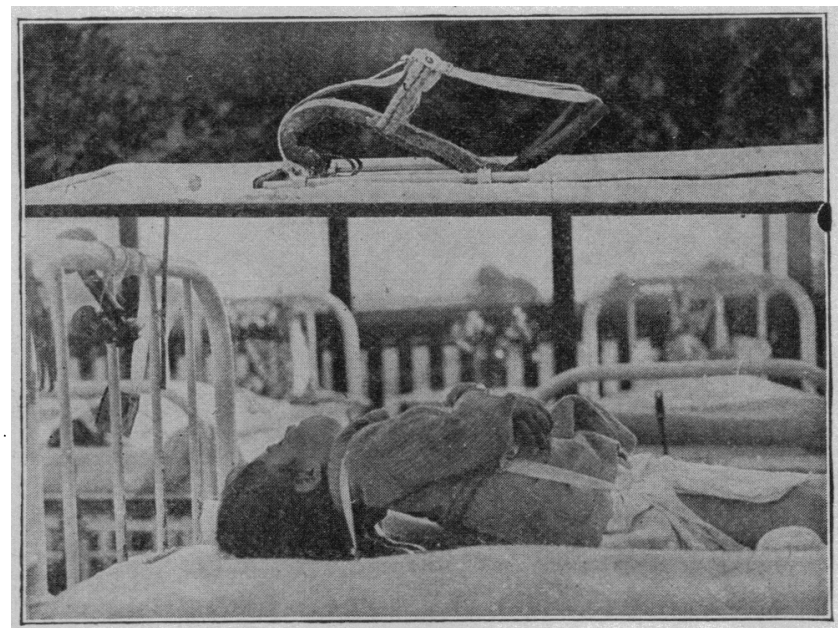

Fig. 7.-Above, special device for tuberculosis of the upper dorsal region (note arrangement of straps and padding); below, patient in position on frame.

kyphos, the weight of the head acts as traction, and usually secures all the extension needed. This is much better than the commonly used plaster bed, owing to the complete ventilation secured, and the ease with which its curve may be adjusted.

In spinal, as in all forms of tuberculous disease, the open air treatment is of vital importance. Therefore, one of the extremely practical features of the device is the ease with which it may be carried about by the nurse in the hospital or the parent at home. The child may even be brought to the physician's office without removal or danger of displacement.

The accompanying photographs cannot fail to make more evident the points I have endeavored to emphasize, particularly the patients' invariable well-being and their normal bodily development while recumbent.

It is with the hope that this appliance may prove of value to others who are interested in the treatment of tuberculous spines that I present it for consideration.

429 Osborn Building.

Treatment of Mental Disorders.-In every large center of population a department for nervous and mental cases should be provided in connection with the best general hospital. This department should be so organized and equipped that the patients would be treated by the most approved methods at the hands of specially trained and experienced nurses and physicians. In no class of case is the necessity for specialists more pressing. In fact special knowledge and skill are the only sure safeguard against gross neglect and mismanagement in the treatment of mental cases.-W. L. Russell, Canadian J. Mental Hygiene 1:161 (July) 1919. 